\title{
Vascular reactivity in the primate brain after acute cryogenic injury
}

\author{
P. L. RE I L L Y ${ }^{1}, J$. K. FARRAR ${ }^{2}$, A N D J . D . M I L LER ${ }^{3}$ \\ From the University Department of Neurosurgery, Institute of Neurological Sciences, and the \\ Wellcome Surgical Research Institute, Glasgow, Scotland
}

S U M MARY The effects of an acute cryogenic injury on cerebral blood flow (CBF) and cerebral vascular reactivity were studied in 12 anaesthetised, ventilated baboons. Autoregulation, defined in this study as intact with a greater than $20 \%$ change in cerebrovascular resistance in response to a change in cerebral perfusion pressure, was tested before the lesion by arterial hypotension. Intact autoregulation was found in half the animals, but all animals showed an increase in CBF with hypercarbia. The cryogenic lesion was followed by a marked rise in intracranial pressure, and a fall in CBF which was only partly related to the status of autoregulation beforehand. After injury, arterial hypertension caused an increase in cerebrovascular resistance of more than $20 \%$ in half the animals. This response was not related to the presence of autoregulation before the lesion, and was accompanied by a greater impairment of the cerebrovascular response to carbon dioxide, more severe brain oedema, and lower cerebral oxygen consumption, than in the remaining baboons which had a pressure passive response to arterial hypertension. This study confirms that the failure of CBF to increase with arterial hypertension may indicate severe brain damage rather than intact physiological autoregulation.

Intact cerebrovascular function is indicated by normal levels of cerebral blood flow (CBF) and by predictable responses of the cerebral circulation to changes in arterial $\mathrm{PCO}_{2}$ (Reivich, 1964; Harper and Glass, 1965), and arterial pressure (Rapela and Green, 1964; Harper, 1966). If these responses are intact, so also will be the responses to hypoxia (McDowall, 1966), hyperoxia (Miller et al., $1970 \mathrm{a}, \mathrm{b})$, and raised intracranial pressure, with or without brain shift (Miller et al., 1972, 1973).

Minimal damage to the brain produced by continuous or intermittent compression will at first impair the autoregulatory responses to changes in arterial pressure at a stage when normotensive normocapnic values for CBF are unchanged

Supported by the Secretary of State for Scotland's Fund for Medical Research (Grant K/MRS/18/C155: JDM) and the Ontario Heart Foundation, Ontario, Canada (JKF).

${ }^{1}$ Address for reprint requests: Dr P. L. Reilly, Department of Neurosurgery, Flinders Medical Centre, Bedford Park, South Australia, 5042.

Present addresses:

2 Department of Biophysics, University of Western Ontario, London, Ontario, Canada, N61, 5A5.

${ }^{3}$ Division of Neurological Surgery, Virginia Commonwealth University, Richmond, Virginia 23298, USA.

Accepted 23 May 1977
(Brock, 1968; Reivich et al., 1969). With this minor degree of trauma, the cerebrovascular response to changes in arterial $\mathbf{P C O}_{2}$ is still present, but if arterial hypertension and hypercapnia are combined, the damaged area of the brain will swell due to a combination of vascular distension and extracellular oedema (Schutta et al., 1968; Marshall et al., 1969).

At a later stage of brain compression, when intracranial pressure (ICP) approaches the level of arterial pressure, and $\mathrm{CBF}$ is reduced, the cerebrovascular response to changes in arterial $\mathrm{PCO}_{2}$ eventually disappears, first to hypercapnia, then to hypocapnia (Langfitt et al., 1965b; Miller et al., $1970 \mathrm{a}$, b). At this preterminal stage, the cerebral vessels will no longer respond to changes in arterial $\mathrm{PO}_{2}$ or to the volatile anaesthetic agent halothane, which is, under normal circumstances, a cerebral vasodilator (Miller et al., 1970a,b; Fitch and Miller, unpublished observations). Langfitt $e t$ al. (1965b) have proposed the term 'cerebral vasomotor paralysis' for this advanced stage of cerebrovascular dysfunction, and has suggested that before this stage is reached, there is a stage of vasomotor paresis which is likely to be more severe 
in some parts of the brain than in others, and with different forms of brain injury.

In the decade since, studies of regional blood flow and cerebrovascular responsiveness have demonstrated focal areas that do not autoregulate or respond to $\mathrm{CO}_{2}$ in patients with brain tumours (Pálvölgyi, 1969), focal cerebral ischaemia (Paulson, 1971; Fieschi and Bozzao, 1972), and posttraumatic cerebral haemorrhage and contusion (Bruce et al., 1973; Overgaard and Tweed, 1974; Enevoldsen et al., 1976). In some areas, dissociation may be found between the $\mathrm{CO}_{2}$ response and the autoregulatory response, where one is lost while the other remains intact. There may also be a global loss of autoregulation and $\mathrm{CO}_{2}$ response. It is not yet clear, however, whether there is an orderly progression of cerebrovascular dysfunction in different forms of brain damage-for example, traumatic, ischaemic, and compressive. Were this so, an assessment of the extent and severity, and perhaps even the aetiology, of a brain lesion might be based on measurement of regional CBF and cerebrovascular responsiveness.

In many types of brain damage encountered clinically, the assessment of cerebrovascular function may be a complex problem. This is particularly so in areas of brain oedema where baseline CBF may be severely reduced at a time when ICP is not greatly increased (Meinig et al., 1973). This dissociation between blood flow and measured cerebral perfusion pressure (arterial pressure minus intracranial pressure) implies a direct effect of oedema on the cerebrovascular resistance. Occlusion or distortion of the capillary bed has been proposed by some authors (Hekmatpanah, 1970; Matakas et al., 1973). Brock (1971), however, has advanced the concept that tissue pressure in areas of brain oedema might exceed measured ventricular pressure. Reduced blood flow might be explained by local reductions of transmural and perfusion pressure. Subsequent work has supported this proposal (Reulen and Kreysch, 1973; Reulen et al., 1975; Brock et al., 1975; Shulman et al., 1975).

Of greater importance than baseline tissue blood flow is the response of the circulation in such damaged areas of the brain to physiological stimuli. It is on this basis that methods of augmenting tissuc perfusion can be proposed. It has been shown that in areas of brain oedema, the response of the vessels to changes in arterial $\mathrm{PCO}_{2}$, particularly elevation, is impaired (Wallenfang et al., 1975). The question arises, then, whether blood flow in areas of brain contusion and oedema can be augmented by elevation of the perfusion pressure, induced by increasing intra- arterial or reducing intracranial pressure. In a previous experimental study (Miller et al., 1975), it was shown that after a cryogenic injury to the primate brain, increases in both arterial pressure and perfusion pressure were not accompanied by parallel increases in cerebral blood flow. This implied that an increase in cerebrovascular resistance in response to rising arterial pressure had occurred in an area of the brain in which autoregulation might reasonably have been expected to be impaired, since the cryogenic lesion was associated with a reduction in baseline regional $\mathrm{CBF}$ and with an increase in ICP. It was tentatively concluded that the failure of CBF to increase in response to a rise in cerebral perfusion pressure in these circumstances did not represent normal physiological pressure autoregulation, but was another aspect of the intracranial pressure-flow dissociation alluded to earlier. The present study is an extension of this investigation, in which we now compare the response of $\mathrm{CBF}$ to increased arterial pressure after cryogenic brain injury with the cerebrovascular response to hypercapnia in the same area, and relate these vascular responses to the severity of brain oedema as measured by the white matter water content in the affected region of the brain.

\section{Methods}

Twelve young adult baboons ( $P$. anubis and $P$. cynocephalus), weighing 9-23 $\mathrm{kg}$, were studied. They were premedicated with phencyclidine $(1 \mathrm{mg} / \mathrm{kg})$. Anaesthesia was induced with intravenous thiopentone $(10 \mathrm{mg} / \mathrm{kg})$ and maintained after endotracheal intubation by a nitrous oxide: oxygen mixture $(75: 25)$, supplemented with intramuscular phencyclidine ( $4 \mathrm{mg}$ every 30 minutes). Artificial ventilation at normocapnia $(40 \mathrm{mmHg}$ $\mathrm{PCO}_{2}$ ) was performed with a modified Starling pump (Palmer), and succinylcholine was administered (100 mg every 30 minutes), to ensure muscular relaxation. Heat lamps maintained normothermia $\left(38^{\circ} \mathrm{C}\right)$, and fluid losses were corrected by slow intravenous infusion.

Systemic arterial pressure (SAP), bilateral intraventricular pressures, end-tidal $\mathrm{CO}_{2}$ concentration, and arterial and sagittal sinus blood gases and oxygen saturation values, were measured as previously described (Miller et al., 1975). The intracranial volume-pressure response was derived from the immediate increase in intraventricular pressure produced by a bolus injection into the lateral ventricle of $0.1 \mathrm{ml}$ of nn:mai saline in one second (Leech and Miller, 19/4). Cerebrel blood flow in the right temporoparietal area vas measured by 
the ${ }^{133}$ xenon technique (Rowan et al., 1970). Values of CBF used in this study are derived from stochastic (height-area) analysis of a 10 minute isotope washout curve, and thus represent mean flow in the area 'viewed' by the collimated detector. Cerebrovascular resistance was derived from cerebral perfusion pressure divided by blood flow. An approximate value of $\mathrm{CMRO}_{2}$ was calculated from the product of CBF and cerebral arteriovenous oxygen content difference (derived from haemoglobin and oxygen saturation values).

EXPERIMENTAL PROTOCOL (TABLE 1)

Two control measurements of CBF were obtained under stable conditions of arterial pressure, blood gases, and intracranial pressure. Autoregulation

Table 1 Summary of protocol

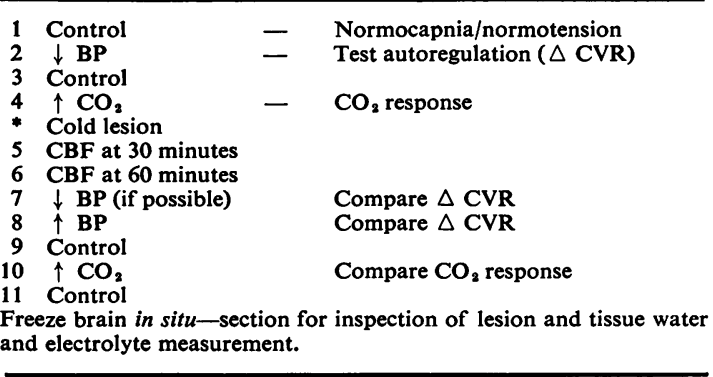

of $\mathrm{CBF}$ was then assessed by reducing arterial pressure by $30 \mathrm{mmHg}$, using controlled haemorrhage. Intact autoregulation was defined as a decrease in cerebrovascular resistance of $20 \%$ or more, any lesser change being categorised as impaired autoregulation (Miller et al., 1975). After reinfusion, and a further control CBF measurement at normal arterial pressure, the cerebrovascular response to hypercapnia was tested by adding sufficient $\mathrm{CO}_{2}$ to the inspired gases to raise arterial $\mathrm{PCO}_{2}$ by $15-20 \mathrm{mmHg}$.

When normocapnia had been resumed, a cryogenic lesion was made in the brain underlying the blood flow detector. The closed end of a metal cylinder (10 $\mathrm{mm}$ diameter) was placed against the intact dura mater through a previously-fashioned burrhole, and filled with liquid nitrogen for measured periods of two to 12 minutes. Cerebral blood flow was measured 30 and 60 minutes after thawing had occurred, the detector being repositioned precisely to record the flow changes in and about the area of the lesion.

Autoregulation was then retested, firstly by reducing arterial pressure by controlled haemorrhage, then by increasing arterial pressure using an intra-aortic infusion of norepinephrine (Miller et al., 1972, 1975), with an intervening normotensive control measurement. It was not possible to test autoregulation to hypotension in all animals, because of a considerable increase in ICP produced by the lesion. Induction of hypotension in these animals would have so reduced cerebral perfusion pressure (to less than $40 \mathrm{mmHg}$ ) as to have ensured cerebral ischaemia whatever the status of autoregulation. After a further control, blood flow was measured during hypercapnia of the same degree as before. Midway through each flow measurement, blood gases, SAP, ICP, and the volume-pressure response were recorded.

Finally, normocapnic and normotensive conditions were resumed, the calvarium was removed as rapidly as possible, and the baboon killed, using intravenous barbiturate. The brain was frozen in situ with liquid nitrogen, then removed and sectioned. Tissue samples were taken from nonhaemorrhagic white matter underlying the cortical lesion and from the equivalent area in the opposite hemisphere. Samples were assayed for water content by wet/dry weight measurements, and for electrolyte content by flame photometry after extraction with nitric acid.

In six baboons, Evans Blue $(1 \mathrm{ml} / \mathrm{kg}$ of $2.5 \%$ solution) was injected intravenously before the cryogenic injury, to assess the extent of the oedema front at the time of death six to nine hours later.

\section{Results}

\section{MEASUREMENT BEFORE CRYOGENIC INJURY}

(TABLE 2)

A control value for cerebral blood flow of $47.8 \pm$ $4.3 \mathrm{ml} / \mathrm{min} .100 \mathrm{~g}$ (SE) was obtained at normocapnia $\left(\mathrm{PaCO}_{2} 39.9 \pm 0.5 \mathrm{mmHg}\right)$ and normotension (SAP $93.7 \pm 2.2 \mathrm{mmHg}$ ). The ventricular pressure for the entire group was $11.8 \pm 1.4 \mathrm{mmHg}$. Higher levels from 13 to $19 \mathrm{mmHg}$ occurred after preparation in four baboons, three of whom were found later to have haemorrhage at the site of the ventricular puncture. No cause for raised pressure was found in the fourth. The volume pressure response was $2.0 \pm 0.4 \mathrm{mmHg} / 0.1 \mathrm{ml}$. Significantly higher values occurred in baboons with raised ICP $(\mathrm{P}<0.001, r=0.81)$. There was no obvious relationship between raised ICP and resting CBF at this stage in the experiment.

Autoregulation was tested by induced arterial hypotension in 11 animals and by hypertension in one. There was no change in mean CBF for the 
Table 2 Control values before cryogenic lesion in baboons with intact and impaired autoregulation $(M \pm S E)$

\begin{tabular}{|c|c|c|c|}
\hline Measurement (units) & $\begin{array}{l}\text { Intact } \\
(n=7)\end{array}$ & $\begin{array}{l}\text { Impaired } \\
(n=5)\end{array}$ & $\begin{array}{l}\text { Whole } \\
\text { group }\end{array}$ \\
\hline $\begin{array}{l}\text { Arterial } \mathrm{PCO}_{2}(\mathrm{mmHg}) \\
\text { Arterial pressure }(\mathrm{mmHg}) \\
\text { Intracranial pressure } \\
\text { (mmHg) } \\
\text { Volume-pressure response } \\
\text { (mmHg/0.1 ml) } \\
\text { Cerebral blood flow } \\
\text { (ml/min. } 100 \mathrm{~g} \text { ) } \\
\mathrm{CMRO}_{2}\end{array}$ & $\begin{array}{r}39.6 \pm 0.7 \\
93.3 \pm 3.4 \\
9.1 \pm 1.1 \\
1.3 \pm 0.3 \\
50.9 \pm 6.8 \\
2.0 \pm 0.1\end{array}$ & $\begin{array}{r}40.2 \pm 0.5 \\
94.0 \pm 2.3 \\
15.4 \pm 1.9 * \\
2.3 \pm 0.8 \\
43.4 \pm 3.9 \\
2.1 \pm 0.2\end{array}$ & $\begin{array}{r}39.9 \pm 0.5 \\
93.7 \pm 2.2 \\
11.8 \pm 1.4 \\
2.0 \pm 0.4 \\
47.8 \pm 4.3 \\
2.1 \pm 0.1\end{array}$ \\
\hline $\begin{array}{l}\text { Response to induced change } \\
\text { Arterial } \mathrm{PCO} \mathrm{O}_{2}(\mathrm{mmHg}) \\
\text { Change in intracranial } \\
\text { pressure (mmHg) } \\
\text { Change in perfusion } \\
\text { pressure (mmHg) } \\
\text { Change in cerebral blood } \\
\text { flow (ml/min. } 100 \mathrm{~g}) \\
\text { Change in cerebro- } \\
\text { vascular resistance }(\%) \\
\mathrm{CMRO}_{2}\end{array}$ & $\begin{aligned} & \text { in } B P \\
& 41.6 \pm 1.2 \\
& 1.0 \pm 0.3 \\
& 18.9 \pm 2.9 \\
& 2.0 \pm 0.8 \\
& 26.1 \pm 3.6 \\
& 2.3 \pm 0.2\end{aligned}$ & $\begin{array}{c}41.4 \pm 0.5 \\
3.0 \pm 0.8 \\
22.6 \pm 3.9 \\
11.2 \pm 2.7^{*} \\
9.0 \pm 3.6 \dagger \\
2.1 \pm 0.4\end{array}$ & $\begin{array}{r}41.1 \pm 0.5 \\
2.1 \pm 0.6 \\
20.4 \pm 2.3 \\
5.8 \pm 1.8 \\
19.3 \pm 3.5 \\
2.2 \pm 0.2\end{array}$ \\
\hline $\begin{array}{l}\text { Response to hypercarbia } \\
\text { Arterial } \mathrm{PCO}_{2}(\mathrm{mmHg}) \\
\text { Arterial pressure }(\mathrm{mmHg}) \\
\text { Intracranial pressure } \\
(\mathrm{mmHg}) \\
\mathrm{CO}_{2} \text { response }(\mathrm{ml} / \mathrm{min} . \\
\left.100 \mathrm{~g} \text { per torr } \mathrm{PaCO}_{2}\right) \\
\mathrm{CMRO}_{2}\end{array}$ & $\begin{array}{r}54.1 \pm 3.0 \\
97.8 \pm 5.9 \\
17.1 \pm 3.0 \\
1.6 \pm 0.3 \\
2.0 \pm 0.3\end{array}$ & $\begin{array}{c}53.0 \pm 1.6 \\
93.6 \pm 4.3 \\
25.6 \pm 5.2 \\
2.9 \pm 0.3 \ddagger \\
2.4 \pm 0.4\end{array}$ & $\begin{array}{r}53.7 \pm 1.8 \\
96.1 \pm 3.8 \\
20.0 \pm 3.2 \\
2.1 \pm 0.1 \\
2.5 \pm 0.2\end{array}$ \\
\hline
\end{tabular}

${ }^{*} \mathrm{P}<0.5 \quad \dagger \mathrm{P}<0.02 \quad \ddagger \mathrm{P}<0.01 \quad$ by paired $t$ test

group as a whole; however, as in previous studies, we assessed this response in individual animals by measuring the change in cerebrovascular resistance (CVR), which is calculated from: CVR $=(\mathrm{MABP}-\mathrm{ICP}) / \mathrm{CBF} \mathrm{mmHg} / \mathrm{ml} / \mathrm{min} .100 \mathrm{~g} . \mathrm{A}$ change of CVR of $20 \%$ or more in the direction of a change in arterial pressure is used as a criterion of intact autoregulation, and any lesser change in CVR indicates impaired autoregulation (Miller et al., 1972, 1975). Using this rather strict definition, only seven baboons were considered to have intact autoregulation. Of the five baboons in which autoregulation was impaired, ICP was raised in three. Thus, mean ICP in those baboons with intact autoregulation was $9.1 \pm 1.1 \mathrm{mmHg}$, while ICP in those with impaired autoregulation was $15.4 \pm$ $1.9 \mathrm{mmHg}(\mathrm{P}<0.05)$.

Hypercapnia produced an increase in CBF in all animals, an average increase in $\mathrm{PaCO}_{2}$ of $15 \mathrm{mmHg}$, resulting in a $41 \%$ increase in flow. This $\mathrm{CO}_{2}$ response was expressed as a $\mathrm{CBF} / \mathrm{CO}_{2}$ gradient of $2.1 \pm 0.1 \mathrm{ml} / \mathrm{min} / 100 \mathrm{~g}$ per torr change in $\mathrm{PaCO}_{2}$, the responses ranging from 0.5 to 3.7 in individual baboons. Paradoxically, the $\mathrm{CO}_{2}$ response was higher in those with impaired autoregulation. The calculated cerebral metabolic rate for oxygen $\left(\mathrm{CMRO}_{2}\right)$ was $2.1 \pm 0.1 \mathrm{ml} / 100 \mathrm{~g} / \mathrm{min}$ and did not alter with variation in either arterial pressure or $\mathrm{PaCO}_{2}$.

\section{CHANGES PRODUCED BY CRYOGENIC INJURY \\ (TABLES 3 AND 4)}

The usual pattern of change after cryogenic brain injury was an increase in ICP accompanied by some increase in MABP beginning at about 10 minutes after the end of the freezing period and coinciding with thawing of the tissues.

\section{Table 3 Effect of cryogenic injury $(M \pm S E)$}

\begin{tabular}{|c|c|c|c|}
\hline \multirow[t]{2}{*}{ Measurement (units) } & \multicolumn{3}{|c|}{ Whole group $(n=12)$} \\
\hline & control & $30 \mathrm{~min}$ & $60 \mathrm{~min}$ \\
\hline \multirow{4}{*}{$\begin{array}{l}\text { Arterial } \mathrm{PCO}_{2}(\mathrm{mmHg}) \\
\text { Arterial pressure }(\mathrm{mmHg}) \\
\text { Intracranial pressure } \\
\text { (mmHg) } \\
\text { Cerebral perfusion } \\
\text { pressure (mmHg) } \\
\text { Cerebral blood flow } \\
\text { Cerebrovascular resistance } \\
(\mathrm{mmHg} / \mathrm{ml} / \mathrm{min} / 100 \mathrm{~g}) \\
\mathrm{CMRO}_{2}\end{array}$} & $\begin{array}{l}40.1 \pm 0.2 \\
89.7 \pm 2.5\end{array}$ & $\begin{array}{l}41.8 \pm 1.0 \\
92.5 \pm 7.6\end{array}$ & $\begin{array}{l}40.7 \pm 0.8 \\
84.7 \pm 4.4\end{array}$ \\
\hline & $12.8 \pm 1.1$ & $28.1 \pm 5.1^{*}$ & $27.2 \pm 4.0 \dagger$ \\
\hline & $\begin{array}{l}76.8 \pm 2.6 \\
48.4 \pm 4.2\end{array}$ & $\begin{array}{l}64.4 \pm 3.9 \ddagger \\
39.7 \pm 3.5 \ddagger\end{array}$ & $\begin{array}{l}57.5 \pm 3.4 \ddagger \\
39.4 \pm 4.2^{*}\end{array}$ \\
\hline & $\begin{array}{c}1.70 \pm 0.12 \\
2.1 \pm 0.1\end{array}$ & $\begin{aligned} 1.81 & \pm 0.24 \ddagger \\
1.9 & \pm 0.2\end{aligned}$ & $\begin{array}{c}1.67 \pm 0.21 \\
1.8 \pm 0.2\end{array}$ \\
\hline
\end{tabular}

When measurements were made 30 and 60 minutes from the end of the freezing period, arterial pressure had returned to control levels, but ICP was significantly raised and cerebral perfusion pressure significantly reduced $(P<0.02$ and $\mathbf{P}<0.01$ ). The volume-pressure response tended to increase at 60 minutes. Cerebral blood flow was reduced at 30 minutes and 60 minutes $(P<0.05)$. When groups of baboons which had intact and impaired autoregulation before injury were analysed separately, however, a significant reduction in $\mathrm{CBF}$ at 60 minutes after cryogenic injury was found only in those animals with impaired autoregulation before the lesion was produced $(P<0.02)$, even though ICP and CPP were not significantly different from the group with intact autoregulation.

\section{CEREBROVASCULAR RESPONSES AFTER CRYOGENIC} INJURY (TABLE 5)

It had been our intention to test autoregulation to a reduction in arterial pressure after the cryogenic injury in all animals. In fact, satisfactory measurements were possible in only two baboons; in the remainder, the postinjury increase in ICP had reduced CPP to the point where any further reduction in perfusion pressure large enough to provide 
Table 4 Effect of cryogenic injury in baboons with intact and impaired autoregulations $(M \pm S E)$

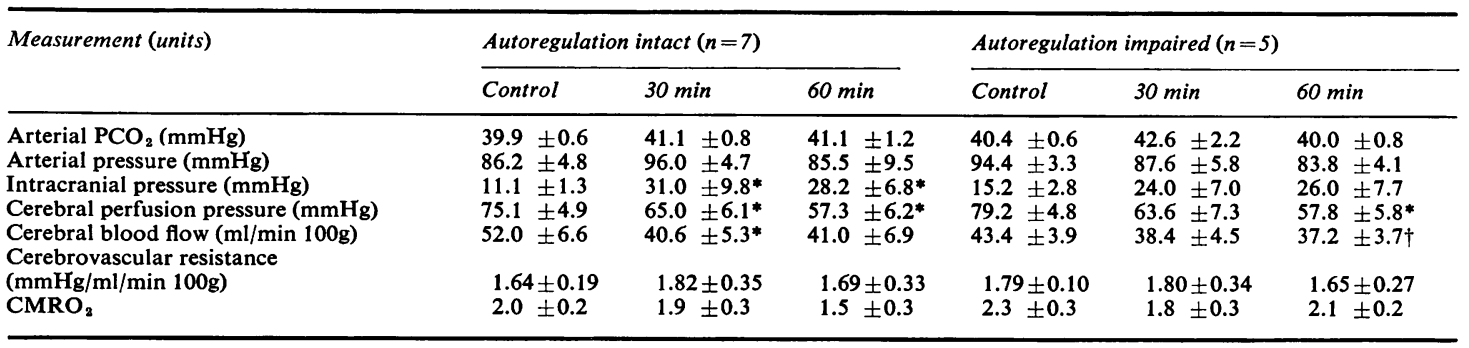

$*_{\mathrm{P}}<0.05 \quad \dagger_{\mathrm{P}}<0.02 \quad$ by paired $t$ test

Values at $30 \mathrm{~min}$ and $60 \mathrm{~min}$ compared with control levels

Table 5 Effect of arterial hypertension after cryogenic lesion in baboons: comparison of groups according to change in cerebrovascular resistance $(M \pm S E)$

\begin{tabular}{|c|c|c|c|c|}
\hline \multirow{2}{*}{ Measurement (units) } & \multicolumn{2}{|c|}{$C V R>20 \%(n=6)$} & \multicolumn{2}{|c|}{$C V R<20 \%(n=6)$} \\
\hline & Control & Experimental & Control & Experimental \\
\hline
\end{tabular}

${ }^{*} \mathrm{P}<0.05 \quad \dagger \mathrm{P}<0.02 \quad \ddagger \mathrm{P}<0.01 \quad$ by paired $t$ test

Value after induced arterial hypertension compared with control levels

a meaningful physiological stimulus would have lowered CPP below the point $(40-50 \mathrm{mmHg}$ ) where autoregulation could have been expected even under normal circumstances. In one of the two animals, autoregulation to hypotension had been intact before the lesion, and this was clearly impaired afterwards in both.

In 12 baboons, the autoregulatory response to an induced increase in arterial pressure of 40-50 $\mathrm{mmHg}$ was then tested. A change of this magnitude was necessary because the accompanying increase in ICP tended to diminish the increase in CPP produced by arterial hypertension. Indeed, in two of the animals, one of whom failed to autoregulate to induce hypotension, rises in SAP of $23 \mathrm{mmHg}$ and $50 \mathrm{mmHg}$ were accompanied by an equal rise in ICP, so that CPP remained constant. The mean passive increase in ICP during arterial hypertension was $18.4 \pm 4.8 \mathrm{mmHg}$, with no obvious relationship between the change in ICP and that produced by the cryogenic lesion, or the status of autoregulation before injury.

Overall, induced arterial hypertension with arterial $\mathrm{PCO}_{2}$ held constant produced an increase in CBF from $41.3 \pm 4.0$ to $50.1 \pm 6.8 \mathrm{ml} / \mathrm{min} 100 \mathrm{~g}$, $(\mathrm{P}<0.05$, on paired $t$ test). From this wide range of values, it is apparent that the response of $\mathrm{CBF}$ to the increase in arterial pressure varied greatly. In six of the 12 baboons there was a rise in CVR of less than $20 \%$ with arterial hypertension. In two of those, CPP did not increase, and CBF remained relatively constant. In four others, arterial hypertension produced an increase in CPP, and CBF increased from $46.0 \pm 9.1$ to $65.8 \pm 13.3 \mathrm{ml} / \mathrm{min}$ $100 \mathrm{~g},(\mathrm{P}<0.01)$.

On the other hand, in the remaining six animals there was a rise of more than $20 \%$ with arterial hypertension and, related to this, there was no significant change in $\mathrm{CBF}$.

This apparent persistence of autoregulatory activity after cryogenic injury was entirely unrelated to the status of autoregulation before injury (Fig. 1). Thus, three of the six baboons which showed apparent autoregulation after injury had had impaired autoregulation beforehand, and three had had intact autoregulation. Of the six animals with impaired autoregulation after injury, it had previously been intact in three and impaired in three.

The response of CBF to hypercapnia was generally reduced after injury compared with the initial response (Fig. 2). In one baboon, administration of 


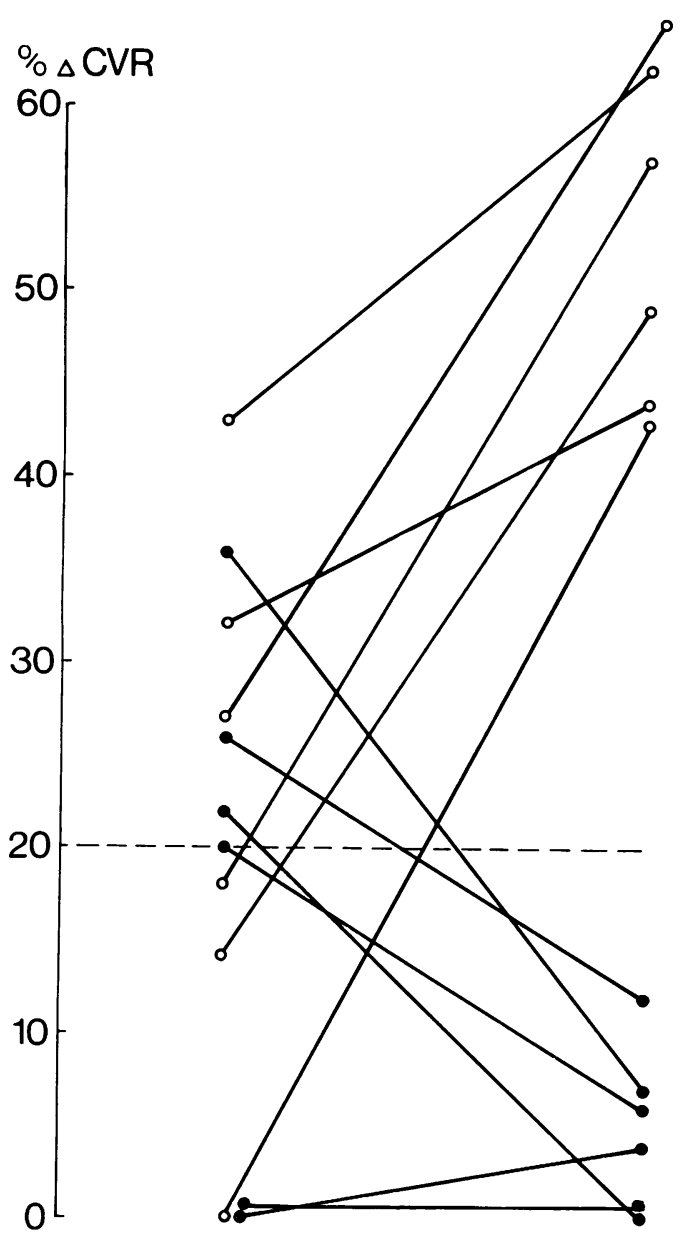

BEFORE
$\mathrm{CO}_{2}$ RESPONSE $\triangle \mathrm{CBF} / \triangle \mathrm{PaCO}_{2}$

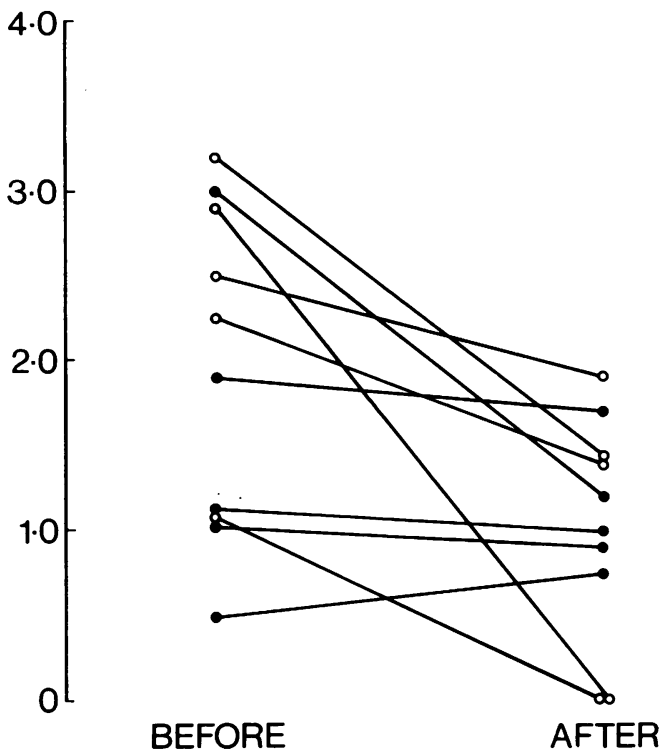

Fig. 1 (left) Response to arterial hypertension before and after cryogenic injury, expressed as a percentage change in cerebrovascular resistance. (right) Cerebrovascular $\mathrm{CO}:$ response before and after injury expressed as change in $\mathrm{CBF}$ per torr change in $\mathrm{PaCO}$ $\mathrm{O}=$ baboons with a greater than $20 \%$ increase in CVR after injury.
$\mathrm{CO}_{2}$ after injury triggered off a massive increase in arterial and intracranial pressure associated with a pronounced increase in CBF: this was not considered to represent a true $\mathrm{CO}_{2}$-induced rise in $\mathrm{CBF}$, and the result in this animal has not been expressed as a $\mathrm{CBF} / \mathrm{CO}_{2}$ gradient. This baboon was one of the six which demonstrated a more than $20 \%$ rise in CVR during post-injury arterial hypertension. The $\mathrm{CO}_{2}$ gradient was reduced in the remaining six baboons in this group, with reversal of the response in two animals, so that CBF in the affected area actually fell during hypercapnia. In the five baboons which demonstrated impaired autoregulation after injury, the $\mathrm{CO}_{2}$ gradient was essentially unchanged, compared with the original level in four cases, and decreased in one.

It appeared, therefore, that persistence of apparent autoregulatory activity after brain injury was associated with a deterioration of the cerebrovascular response to $\mathrm{CO}_{2}$ in the injured hemisphere. A pressure-passive response of CBF to increased perfusion pressure, on the other hand, was associated with some retention of responsiveness of the cerebral circulation to hypercapnia.

The volume-pressure response showed a further 


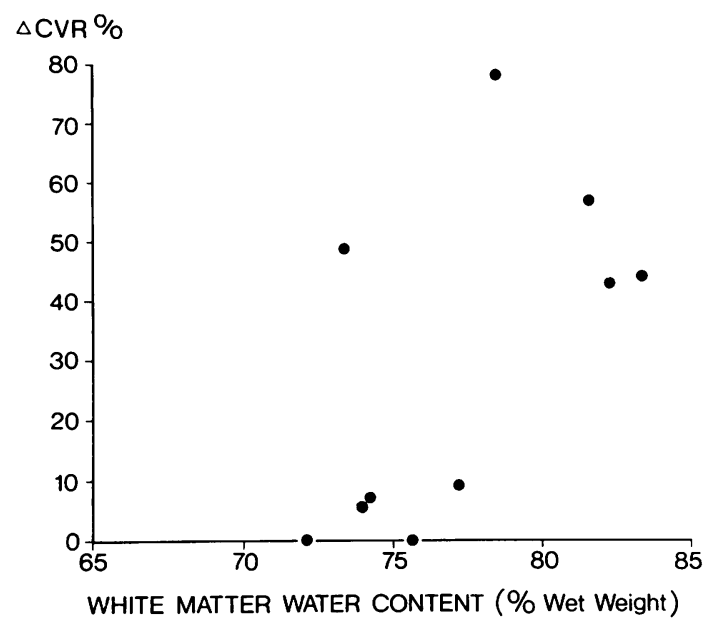

Fig. 2 Relationship between white matter water content deep to cryogenic lesion and cerebrovascular response to induced arterial hypertension $(\mathrm{r}=0.60$, $\mathbf{P}<0.05$ ).

increase with arterial hypertension after the lesion had been produced, but not with induced hypercapnia.

BRAIN WATER CONTENT AND CEREBROVASCULAR RESPONSE (TABLE 6)

White matter water content in the right cerebral hemisphere underlying the visible cortical lesion was increased in all animals with levels ranging from 72.1 to $83.4 \%$ of wet weight. These values can be compared with the water content of the equivalent area in the opposite hemisphere (71.1士 $0.4 \%$ ). In animals receiving Evans Blue as a tracer, the underlying oedematous white matter in all cases showed a visible blue staining on brain section. There was a positive correlation between the water content of the affected white matter and the extent to which cerebrovascular resistance rose during induced arterial hypertension. Thus, the four highest values of brain water content were all found in animals which had a greater than $20 \%$ increase in CVR. Overall, the correlation between white matter water content and percentage change in CVR was significant $(r=0.60 ; \mathrm{P}<0.05)$ (Fig. 2).

The extent to which the ICP and the volumepressure response increased was not related to the level of water-content in the affected white matter.

CEREBRAL METABOLIC RATE AND VASCULAR RESPONSIVENESS

Low calculated values for $\mathrm{CMRO}_{2}$ occurred in those baboons which demonstrated a large increase in CVR during induced arterial hypertension. There was a wide scatter of results, however, and the overall difference in $\mathrm{CMRO}_{2}$ between the groups of baboons with impaired $(2.4 \pm 0.4 \mathrm{ml} /$ $100 \mathrm{~g} / \mathrm{min}$ ) and those with apparently persisting $(1.7 \pm 0.2 \mathrm{ml} / 100 \mathrm{~g} / \mathrm{min})$ autoregulation after injury just failed to attain statistical significance. $\mathrm{CMRO}_{2}$ showed a negative correlation with the height of ICP $(r=0.69, \mathrm{P}<0.02)$ but not with the level of brain water content.

\section{Conclusions}

Before producing a cryogenic brain lesion, two groups of animals could be distinguished by testing the cerebral vasomotor response to induced hypotension. Both groups of baboons with intact and impaired autoregulation had, however, normal resting levels of cerebral blood flow and a vasodilator response to hypercarbia.

In any study in which autoregulation is assessed, the criteria used to define 'intact' autoregulation must be stated clearly. Before the cryogenic lesion, arterial hypotension was accompanied by a change in CVR in a direction to normalise blood flow, indicating the presence of autoregulating activity in all but two animals. However, by the definition used in this study, only seven animals had intact autoregulation. Such a division is to some extent arbitrary. Indeed, in other respects these two groups differed only in a slightly higher intracranial pressure in the group with impaired autoregulation. By identifying and retaining this group whose response to a strictly defined test of autoregulation was impaired, it was possible to aid the interpretation of the effects of arterial hypertension after injury.

After focal cryogenic lesions of different dura-

Table 6 Water and electrolyte content related to cerebrovascular response to induced hypertension (M士SE)

\begin{tabular}{lccc}
\hline & $C V R<20 \%$ & CVR $>20 \%$ & Opposite hemisphere \\
\hline Water (\% wet weight) & $74.6 \pm 0.8 \dagger$ & $79.9 \pm 1.6 \ddagger$ \\
Sodium (mmol/g dry weight) & $0.296 \pm 0.017$ & $\mathbf{7 1 . 1} \pm 0.4$ & $0.394 \pm 0.029 *$ \\
\hline
\end{tabular}

${ }^{*} \mathrm{P}<0.05 \quad \dagger \mathrm{P}<0.01 \quad \ddagger \mathrm{P}<0.001$

Values after injury compared with opposite hemisphere 
tion, blood flow was reduced to a degree which was only partly related to the previous status of autoregulation.

An induced increase in arterial pressure which was sufficient to raise cerebral perfusion pressure significantly had a variable effect on blood flow in the area of injured brain. Three types of response could be identified: an increase in cerebral blood flow in proportion to the increase in perfusion pressure, with no change in cerebrovascular resistance-a passive pressure response; secondly, little change in cerebral blood flow, but a parallel increase in intracranial pressure, so that perfusion pressure remained constant; finally, little change in CBF, despite a significant rise in perfusion pressure.

The dissociation between perfusion pressure and blood flow in this third group implies an increase in cerebrovascular resistance. Increase in cerebrovascular resistance was associated with a greater impairment of the cerebrovascular response to carbon dioxide, with higher levels of brain water content-that is, more pronounced brain oedemaand with lower levels of calculated cerebral oxygen consumption compared with animals in which autoregulation was quite clearly impaired.

It appears, therefore, that when the brain is injured, a rise in cerebrovascular resistance produced by increasing arterial and perfusion pressure is a manifestation not of normal physiological autoregulation but, conversely, of a severe degree of brain damage.

\section{Discussion}

Within a normal range of perfusion pressure, cerebral blood flow is held constant by changes in cerebrovascular resistance. In many types of brain damage this important mechanism is lost and perfusion pressure and cerebral blood flow become linearly related. In states of advanced intracranial hypertension, when cerebral elastance is high, an increase in arterial pressure may be accompanied by a parallel increase in ICP, so that CPP remains constant. A constant cerebral blood flow in these circumstances has been termed 'false autoregulation', yet the response is quite predictable from a 'pressure-passive' relationship between perfusion pressure and cerebral blood flow, and unchanging cerebrovascular resistance.

After the cryogenic injury, a constant cerebral blood flow in the face of an increase in perfusion pressure implies either that the normal mechanism for autoregulation is intact, which in these experiments was clearly unlikely, or that some other mechanism exists in damaged brain to prevent a rise in CBF by increasing cerebrovascular resistance. In states of brain damage, particularly those associated with cerebral oedema, resting levels of blood flow may be low when ICP is not particularly high, and reduction in flow is closely related to tissue water content. Some of this reduction may be due to increased tissue volume, so that CBF per unit volume is decreased. Although this might explain a reduction in resting flow, it does not explain a loss of reactivity.

A second effect of increased tissue water content is to increase tissue pressure. Calculation of effective perfusion pressure and transmural pressure within the oedematous tissue might, therefore, be based more properly upon tissue pressure rather than intracranial or cerebral venous pressure. It is well known that arterial hypertension will augment oedema formation. It might be speculated that by driving fluid into the extravascular compartment and increasing tissue pressure, arterial hypertension induces a form of passive autoregulation, analogous to that once postulated in the renal vascular bed (Hinshaw et al., 1959). However, as we have previously discussed (Miller et al., 1975), changes in tissue pressure would need to be well in excess of measured ipsilateral ventricular pressure to negate the apparent increase in cerebrovascular resistance in these studies.

Damage to the blood brain barrier might allow vasoactive blood-borne metabolites to enter the extracellular space. We were concerned that exogenous noradrenaline, used to induce arterial hypertension, might act directly on the cerebral vasculature to increase cerebrovascular resistance. However, studies in which the blood brain barrier has been opened deliberately by osmotic agents suggest that noradrenaline increases rather than decreases cerebral blood flow and metabolism (MacKenzie et al., 1975). Finally, a reduction in metabolic rate might occur after injury, perhaps secondary to release of tissue metabolites. However, a reduced metabolic rate, while lowering regional blood flow, would not explain an increase in cerebrovascular resistance.

Although the mechanism of this abnormal response of damaged brain remains obscure, this study shows that some form of regulation of flow during hypertension remains present beyond the stage where other indices of cerebrovascular responsiveness have been lost. This has significance for the clinician attempting to assess the functional state of the cerebral vasculature, and wishing to improve cerebral blood flow in areas of brain damage. The dangers of attempting to increase cerebral perfusion by inducing arterial hypertension are clear; not only may CBF not increase, 
but oedema formation will be accelerated and, by increasing cerebral elastance, the brain will be rendered more susceptible to acute rises of intracranial pressure (Leech and Miller, 1974). Similarly, hypercarbia may raise intracranial pressure, increase oedema formation, and may even reduce CBF in the damaged areas.

Without measuring regional blood flow, it may not be possible to assess the affects of different therapies; however, the present study would suggest that methods aimed at reducing oedema formation and lowering cerebral vascular resistance, perhaps by lowering tissue pressure, are an essential part of any attempt to increase perfusion in areas of brain damage, and are likely to prove superior to attempts to increase cerebral blood flow directly.

\section{References}

Brock, M. (1968). Regional cerebral blood flow (r CBF) changes following local brain compression in the cat. Scandinavian Journal of Clinical and Laboratory Investigation, Supplement 102, XIVA.

Brock, M. (1971). Cerebral blood flow and intracranial pressure changes associated with brain hypoxia. In Brain Hypoxia, pp. 14-19. Edited by J. B. Brierley and B. S. Meldrum. Heinemann: London.

Brock, M., Furuse, M., Weber, R., Hasuo, M., and Dietz H. (1975). Brain tissue pressure gradients. In Intracranial Pressure II, pp. 215-217. Edited by N. Lundberg, U. Ponten, and M. Brock. Springer: Berlin.

Bruce, D. A., Langfitt, T. W., Miller, J. D., Schutz, H., Vapalahti M., Stanek, A., and Goldberg, H. I. (1973). Regional cerebral blood flow, intracranial pressure and brain metabolism in comatose patients. Journal of Neurosurgery, 38, 131-144.

Enevoldsen, E. M., Cold, G., Jensen, F. T., and Malmros, R. (1976). Dynamic changes in regional $\mathrm{CBF}$, intraventricular pressure, CSF $\mathrm{pH}$ and lactate lcvels during the acute phase of head injury. Journal of Neurosurgery, 44, 191-214.

Fieschi, C., and Bozzao, L. (1972). Clinical aspects of regional cerebral blood flow. Progress in Brain Research, 35, 387-410.

Harper, A. M. (1966). Autoregulation of cerebral blood flow: influence of arterial blood pressure on the blood flow through the cerebral cortex. Journal of Neurology, Neurosurgery, and Psychiatry, 29, 398-403.

Harper, A. M., and Glass, H. I. (1965). Effects of alterations in the arterial carbon dioxide tension on the blood flow through the cerebral cortex at normal and low arterial blood pressures. Journal of Neurology, Neurosurgery, and Psychiatry, 28, 449452.

Hekmatpanah, J. (1970). Cerebral circulation and perfusion in experimental increased intracranial pressure. Journal of Neurosurgery, 32, 21-29.
Hinshaw, L. B., Day, S. B., and Carlson, C. H. (1959). Tissue pressure as a causal factor in the autoregulation of blood flow in the isolated perfused kidney. American Journal of Physiology, 197, 309-312.

Langfitt, T. W., Kassell, N. F., and Weinstein, J. D. (1965a). Cerebral blood flow with intracranial hypertension. Neurology (Minneapolis), 15, 761-733.

Langfitt, T. W., Weinstein, J. D., and Kassell, N. F. (1965b). Cerebral vasomotor paralysis produced by intracranial hypertension. Neurology (Minneapolis), 15, 622-641.

Leech, P. J., and Miller, J. D. (1974). Intracranial volume-pressure relationships during experimental brain compression in primates. Journal of Neurology, Neurosurgery, and Psychiatry, 37, 1093-1111.

MacKenzie, E. T., McCulloch, J., Pickard, J. D., and Harper, A. M. (1975). Cerebral circulatory and metabolic effects of endogenous noradrenalin. In Blood Flow and Metabolism in the Brain, pp. 1.281.31. Edited by A. M. Harper, W. B. Jennett, J. D. Miller, and J. O. Rowan. Churchill-Livingstone: Edinburgh.

McDowall, D. G. (1966). Interrelationships between blood oxygen tensions and cerebral blood flow. International Anaesthesiology Clinics, 4, 205-219.

Marshall, W. J. S., Jackson, J. L. F., and Langfitt, T. W. (1969). Brain swelling caused by trauma and arterial hypertension. Archives of Neurology (Chicago), 21, 545-553.

Matakas, F., Cervos-Navarro, J., and Schneider, H. (1973). Experimental brain death. I. Morphology and fine structure of the brain. Journal of Neurology, Neurosurgery, and Psychiatry, 36, 497-508.

Meinig, G., Reulen, H. J., and Magawly, Chr. (1973). Regional cerebral blood flow and cerebral perfusion pressure in global brain edema induced by water intoxication. Acta Neurochirurgica, 29, 1-13.

Miller, J. D., Fitch, W., Ledingham, I. McA., and Jennett, W. B. (1970a). The effect of hyperbaric oxygen on experimentally increased intracranial pressure. Journal of Neurosurgery, 33, 281-286.

Miller, J. D., Ledingham, I. McA., and Jennett, W. B. (1970b). Effects of hyperbaric oxygen on intracranial pressure and cerebral blood flow in experimental cerebral oedema. Journal of Neurology, Neurosurgery, and Psychiatry, 33, 745-755.

Miller, J. D., Stanek, A. E., and Langfitt, T. W. (1972). Concepts of cerebral perfusion pressure and vascular compression during intracranial hypertension. In Cerebral Blood Flow, Progress in Brain Research, vol. 35, pp. 411-432. Edited by J. S. Meyer and J. P. Schade. Elsevier: Amsterdam.

Miller, J. D., Stanek, A. E., and Langfitt, T. W. (1973). Cerebral blood flow regulation during experimental brain compression. Journal of Neurosurgery, 39, 186-196.

Miller, J. D., Garibi, J., North, J. B., and Teasdale, G. M. (1975). Effects of increared arterial pressure on blood flow in the damaged brain. Journal of Neurology, and Psychiatrv. 38, 657-665.

Overgaard, J., and Tweed, W. A. (1974). Cerebral circulation after head injury. Part I: Cerebral blood 
flow and its regulation after closed head injury with emphasis on clinical correlations. Journal of Neurosurgery, 41, 531-541.

Pálvölgyi, R. (1969). Regional cerebral blood flow in patients with intracranial tumours. Journal of Neurosurgery, 31, 149-163.

Paulson, O. B. (1971): Cerebral apoplexy (stroke): Pathogenesis, pathophysiology and therapy as illustrated by regional blood flow measurements in the brain. Stroke, 2, 327-360.

Rapela, C. E., and Green, H. D. (1964). Autoregulation of cerebral blood flow. Circulation Research, Supplement 1, 15, 205-211.

Reivich, M. (1964). Arterial $\mathrm{pCO}_{2}$ and cerebral hemodynamics. American Journal of Physiology, 206, 25-35.

Reivich, M., Marshall, W. J. S., and Kassell, N. (1969). Loss of autoregulation produced by cerebral trauma. In Cerebral Blood Flow, pp. 205-208. Edited by M. Brock, C. Fieschi, D. H. Ingvar, N. A. Lassen, and $K$. Schürmann. Springer: Berlin.

Reulen, H. J., and Kreysch, H. G. (1973). Measurement of brain tissue pressure in cold induced edema. Acta Neurochirurgica, 29, 29-40.

Reulen, H. J., Graham, R., and Klatzo, J. (1975). Development of pressure gradients within brain tissue during the formation of vasogenic brain edema. In Intracranial Pressure II, pp. 233-238. Edited by $\mathrm{N}$. Lundberg, U. Pontén, and M. Brock, Springer: Berlin.

Rowan, J. O., Harper, A. M., Miller, J. D., Tedeschi, G. M., and Jennett, W. B. (1970). Relationship between volume flow and velocity in the cerebral circulation. Journal of Neurology, Neurosurgery, and Psychiatry, 33, 733-738.

Schutta, H. S., Kassell, N. F., and Langfitt, T. W. (1968). Brain swelling produced by arterial hypertension-a light and electron microscopic study. Brain, 91, 281-294.

Shulman, K., Marmarou, A., and Weitz, S. (1975). Gradients of brain interstitial fluid pressure in experimental brain infusion and compression. In Intracranial Pressure II, pp. 221-223. Edited by N. Lundberg, U. Pontén, and M. Brock. Springer: Berlin.

Wallenfang, T., Schubert, R., Reulen, H. J., and Schurmann, K. (1975). r CBF and regional energy metabolism in cold-injury edema following moderate and severe hypocapnia or hypercapnia. In Cerebral Circulation and Metabolism, pp. 99-101. Edited by T. W. Langfitt, L. C. McHenry, M. Reivich, and H. Wollman. Springer: Berlin. 